\title{
Quantitative Relationships Between Different Injury Factors and Development of Brown Rot Caused by Monilinia fructigena in Integrated and Organic Apple Orchards
}

\author{
I. J. Holb and H. Scherm
}

First author: Centre of Agricultural Sciences, University of Debrecen, P.O. Box 36, H-4015 Debrecen, Hungary; second author: University of Georgia, Department of Plant Pathology, Athens 30602.

Accepted for publication 17 August 2007.

\begin{abstract}
Holb, I. J., and Scherm, H. 2008. Quantitative relationships between different injury factors and development of brown rot caused by Monilinia fructigena in integrated and organic apple orchards. Phytopathology 98:79-86.

In a 4-year study, the incidence of various types of injuries (caused by insects, birds, growth cracks, mechanical wounding, and other, unidentified factors) was assessed in relation to brown rot development (caused by Monilinia fructigena) on fruit of three apple cultivars (Prima, Jonathan, and Mutsu) in integrated and organic blocks of two apple orchards in Hungary. In addition, populations of male codling moths (Cydia pomonella) were monitored with pheromone traps season-long in both management systems. On average, injury incidence on fruit at harvest was 6.1 and $19.2 \%$ in the integrated and organic treatments, respectively. Insect injury, which was caused primarily by $C$. pomonella, had the highest incidence among the five injury types, accounting for $79.4 \%$ of the total injury by harvest in the organic blocks and $36.6 \%$ in the integrated blocks. Levels of all other injury types remained close to zero during most of the season, but the incidence of bird injury and growth cracks increased markedly in

(20.1\% average incidence). In addition, the disease developed later but attained higher levels as the cultivar ripening season increased from earlymaturing Prima to late-maturing Mutsu. Overall, 94.3 to $98.7 \%$ of all injured fruit were also infected by $M$. fructigena, whereas the incidence of brown-rotted fruit without visible injury was very low (0.8 to $1.6 \%)$. Correlation coefficients (on a per plot basis) and association indices (on a per-fruit basis) were calculated between brown rot and the various injury types for two selected assessment dates 4 weeks preharvest and at harvest. At both dates, the strongest significant $(P<0.05)$ relationships were observed between brown rot and insect injury and between brown rot and the cumulative number of trapped $C$. pomonella. At the harvest assessment, two additional significant correlations were between brown rot and bird injury and between brown rot and growth cracks. In every case, correlation coefficients were larger in organic than in integrated blocks. Although it is well established that brown rot in pome fruits is closely associated with fruit injuries, this is the first study to provide season-long progress data on different injury types and quantitative analyses of their relative importance at different times in the growing season and across two distinct management systems.
\end{abstract} the final 3 to 5 weeks before harvest in both production systems. Brown rot developed more slowly and reached a lower incidence in the integrated (6.4\% final incidence on average) compared with the organic blocks
Additional keywords: disease management, Malus domestica, pest management, wounding agents.
Monilinia fructigena Honey is an important fungal pathogen causing pre- and postharvest fruit rot in pome fruits $(3,8)$. The pathogen belongs to the group of brown rot fungi which includes two other economically important species, M. laxa and $M$. fructicola. Losses in apple caused by $M$. fructigena are variable, with decay incidence at harvest ranging from low levels $(\leq 5 \%)$ in well-managed commercial apple orchards $(4,29,38,48)$ to severe levels in organic (up to 46\%) (16) and unsprayed orchards (50 to $90 \%)(6,14)$

Conidia, initially from overwintered fruit mummies and later from symptomatic fruit infected during the growing season, serve as the main inoculum for brown rot infections $(7,8,37)$. These conidia can germinate over a wide temperature range when humidity is high (47). However, M. fructigena, in contrast to $M$. laxa or $M$. fructicola, can infect fruit only via fresh or partially healed wounds $(8,46)$. In general, infection of ripe apples via lenticels $(20,34)$ or fruit-to-fruit contact $(38)$ occurs only at low frequencies, although a study by $\mathrm{Xu}$ et al. (48) attributed up to $44.4 \%$ of all brown rot infections on Cox apple to contact spread. When a mature fruit is wounded, conidia can germinate and infect

Corresponding author: I. J. Holb; E-mail address: holb@agr.unideb.hu

doi:10.1094/PHYTO-98-1-0079

(c) 2008 The American Phytopathological Society the fruit within as little as $2 \mathrm{~h}$, and the pathogen may be able to infect without additional fruit wetness because of the presence of free moisture on the fresh wound surface (47). Latent infections of immature fruit as described for M. fructicola do not occur for M. fructigena (8).

In field conditions, wounds penetrating the fruit skin can be caused by various abiotic or biotic factors, including insects such as the codling moth (Cydia pomonella) $(15,16,29,48)$, the Oriental fruit moth (Cydia molesta) (14), tortrix moths (Pandemis and Adoxophyes spp.) (48), the European earwig (Forficula auricularia) (12), and various species of wasps $(26,48)$; birds such as starlings (Sturnus vulgaris), blackbirds (Turdus merula), and crows (Corvus spp.) $(28,36,38,48)$; growth cracks $(8,48)$, especially in years with late frosts or excessive rainfall; and mechanical injury due to wind storms or hail (48). Although previous research in Britain assessed the relative importance of different injury types (growth cracks and wounds caused by insects and birds) for $M$. fructigena in integrated and conventionally managed apple orchards $(29,48)$, fruit rot incidence was low in these well-managed orchards, which limited the ability to quantify the relative importance of wounding agents for brown rot development. Indeed, it is reasonable to assume that the relative role of each injury factor varies depending on the efficacy of disease and arthropod management programs in a given orchard. For example, in an organic orchard with a less effective pest 
management program $(18,22,33)$, the importance of the various wounding agents may differ markedly from that of an orchard in which conventional pesticides are applied. Moreover, the relative importance of different injury factors may change as the season progresses, which may alter the strength of the association between brown rot and a given wounding agent. The seasonal dynamics of different injury types on apple fruit has not been documented previously.

The objectives of this study were to quantify the temporal progress of the incidence levels of brown rot and different injury types in organic and integrated apple orchards and to determine associations between brown rot and each injury type at different times during the growing season to evaluate potential implications for brown rot management. To increase the scope of the study, assessments were made at two locations and on three cultivars differing in maturity time.

\section{MATERIALS AND METHODS}

Orchard sites. The study was carried out in two commercial high-density apple orchards in the Nagykálló and Eperjeske regions in eastern Hungary between 2002 and 2005. Both orchards were $>9$ ha in area and consisted of two large blocks corresponding to integrated and organic management systems, each comprised of at least 54 tree rows. Different apple cultivars were arranged in a three-row and a two-row cultivar system in the integrated and organic blocks, respectively. Trees at both sites had been planted in 1996 on M26 rootstock, were $>2.5 \mathrm{~m}$ tall, pruned to spindle shape, and were not irrigated. A 0.5 -m-wide strip of bare soil was maintained in the rows, and the grass cover in the row middles was cut four times each year (early June, early July, early August, and early September) in the integrated blocks and twice a year (early July and early September) in the organic blocks. A more detailed description of the two orchard sites and the general horticultural practices applied to them is given elsewhere (19).

Experimental design and treatments. At both sites, four 500tree plots each were randomly placed in the integrated and organic orchard blocks. Each of these plots was subsequently divided into three 150-tree subplots corresponding to early-, mid-, and late-season cultivars Prima, Jonathan, and Mutsu, respectively. Since the four 500-tree treatment plots were not independent from each other (they were located within the same integrated or organic block), data from these plots were averaged, and the 4 years were used as replications in subsequent analyses. As such, the experimental design was a split-plot with the 4 years as replications, the two management systems as main-plots, and the three cultivars as subplots.

The pest management program in the integrated main plots followed the Hungarian integrated fruit production (IFP) guidelines, whereas those in the organic main plots were according to the Hungarian organic production guidelines derived from the European IFP (11) and the International Federation of Organic Agriculture Movements (IFOAM) guidelines (21). Both sets of guidelines had been applied since the orchards were planted in 1996. Fungicide, insecticide, and herbicide active ingredients and application schedules used in the two production systems were similar to those described previously $(18,19)$. All sprays were applied with a Kertitox 2000 axial blower airblast sprayer (Debreceni Gépgyár B. V., Debrecen, Hungary) with a ceramic hollow cone at 1.1 to $1.2 \mathrm{MPa}$ with a volume of 1,000 liters ha ${ }^{-1}$.

Brown rot assessment. Within each subplot, five trees were selected randomly for disease assessment every 7 to 9 days from 20 May until harvest (early September, second half of September, and mid-October for Prima, Jonathan, and Mutsu, respectively). Fifty randomly selected fruit per cultivar typical of the given phenological stage were observed on these trees (without removal) and assessed for disease incidence and severity $\left(\mathrm{cm}^{2}\right.$ of sporulating area per fruit) as described previously (19). A similar evaluation was also made at 4 weeks preharvest and at the final assessment date (harvest) on all dropped fruit on the ground underneath the tree.

Injury assessment. All fruit subjected to brown rot assessment were also assessed for injury. Thus, presence or absence of brown rot and injury was known at the individual fruit level. Five injury types were distinguished and expressed as percent injury incidence per subplot: (i) insect injury, with at least one entry site and/or bite mark visible; (ii) bird injury; (iii) growth cracks; (iv) mechanical injury, showing hail marks or wounding due to strong winds or similar factors; and (v) other injuries for which no specific cause could be identified. When more than one injury type was present on a given fruit, an attempt was made to identify the primary (older) injury so that the total sum of injury types would not exceed $100 \%$. Across all treatments, locations, and years, only 1.2 and $4.9 \%$ of the fruit in the tree had more than one injury type present at 4 weeks before harvest and at harvest, respectively; as such, the potential bias introduced by focusing on the primary injury in our analyses was considered negligible.

Insect injuries were further classified on fruit collected on the last assessment dates in June, July, August, and at harvest. Thirty randomly selected insect-injured fruit per subplot were detached, dissected, and the presence of or typical damage symptoms associated with larvae and/or adult insects were identified. If symptoms were not typical and/or no causative insects were present, then insect injury was classified as unidentified insect injury. A similar assessment was also made on samples of 30 dropped fruit on the ground underneath each tree at 4 weeks preharvest and at the final assessment date at harvest. Altogether, 117,242 fruit were assessed for injury and brown rot across the 4 years.

Monitoring of $\boldsymbol{C}$. pomonella. Numbers of male $C$. pomonella were monitored with three pheromone traps (ARCO-PHERON AM; Hungarian Kwizda Ltd., Budapest, Hungary) per 500-tree main plot from 20 May until 30 September each year. The traps were baited with $1 \mathrm{mg}$ of synthetic codlemone (Shin-etsu Fine Chemical Division, Tokyo, Japan) and hung 1.5 to $2.0 \mathrm{~m}$ above ground in the trees near the center of each 500-tree main plot, keeping at least a $10-\mathrm{m}$ distance among traps. Traps were checked every 2 to 3 days during the season and the number of male moths captured was recorded. Pheromone baits were changed at 5-week intervals, and the sticky capture sheets were replaced 6 to 12 times per year depending on the capture density.

Data analyses. Brown rot incidence and severity data as well as injury incidence data were plotted over time to obtain progress curves for each year. Data from the final assessment date at harvest were subjected to split-plot analysis of variance (ANOVA) separately for the two locations (SAS version 8.1; SAS Institute Inc., Cary, NC). Prior to the analyses, values were transformed using the arcsine-square root transformation to stabilize variances. Since $C$. pomonella trap data were not collected separately by cultivar (subplot), cumulative population numbers of trapped codling moth males were analyzed by one-way ANOVA with management as a treatment factor and years as replications.

Pearson's correlation coefficients were calculated between brown rot incidence and the various injury incidence levels using data summarized on a subplot basis. This analysis was done separately for the two management systems as well as for an early assessment date (4 weeks preharvest) and the final assessment date at harvest using Genstat 5 Release 4.1 (Lawes Agricultural Trust, IACR, Rothamsted, UK). Linear regression functions were then fitted and a $t$ test was used to determine whether the regression slopes were significantly $(P<0.05)$ different between the two management systems.

In addition to these gross plot-based correlations, interspecific associations on an individual fruit basis between presence or absence of brown rot and presence or absence of each injury type 


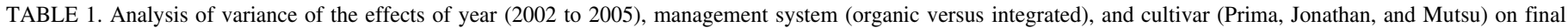
incidence $^{\mathrm{a}}$ of brown rot and various injury types in apple orchards at Eperjeske and Nagykálló, Hungary

\begin{tabular}{|c|c|c|c|c|c|c|c|c|c|c|c|c|c|c|c|c|c|c|c|}
\hline \multirow[b]{2}{*}{ Source } & \multicolumn{4}{|c|}{ Brown rot } & \multicolumn{3}{|c|}{ Insect injury } & \multicolumn{3}{|c|}{ Bird injury } & \multicolumn{3}{|c|}{ Growth cracks } & \multicolumn{3}{|c|}{ Mechanical injury } & \multicolumn{3}{|c|}{$\begin{array}{l}\text { Other (unidentified) } \\
\text { injuries }\end{array}$} \\
\hline & df & MS & $F$ & $P$ & MS & $F$ & $P$ & MS & $F$ & $P$ & MS & $F$ & $P$ & MS & $F$ & $P$ & MS & $F$ & $P$ \\
\hline \multicolumn{20}{|l|}{ Eperjeske } \\
\hline Year (Y) & 3 & 19.133 & 20.12 & 0.003 & 10.633 & 5.91 & 0.032 & 0.175 & 1.44 & 0.322 & 0.064 & 0.65 & 0.614 & 0.007 & 0.39 & 0.764 & 0.161 & 0.73 & 0.692 \\
\hline Management (M) & 1 & 951.300 & 1000.20 & $<0.001$ & 874.290 & 485.65 & $<0.001$ & 0.617 & 5.05 & 0.066 & 1.481 & 14.99 & 0.008 & 0.002 & 0.09 & 0.777 & 0.134 & 0.56 & 0.765 \\
\hline Main plot error & 3 & 2.382 & & & 3.650 & & & 0.189 & & & 0.091 & & & 0.087 & & & 0.032 & & \\
\hline Cultivar (C) & 2 & 30.602 & 32.17 & $<0.001$ & 11.091 & 6.16 & 0.035 & 0.699 & 5.72 & 0.041 & 0.708 & 7.17 & 0.026 & 0.069 & 3.55 & 0.096 & 0.197 & 0.89 & 0.598 \\
\hline $\mathrm{M} \times \mathrm{C}$ & 2 & 2.542 & 2.67 & 0.148 & 0.775 & 0.43 & 0.669 & 0.581 & 4.75 & 0.058 & 0.154 & 1.56 & 0.285 & 0.019 & 0.97 & 0.430 & 0.165 & 0.76 & 0.688 \\
\hline Subplot error & 6 & 0.951 & & & 1.800 & & & 0.122 & & & 0.099 & & & 0.019 & & & 0.211 & & \\
\hline \multicolumn{20}{|l|}{ Nagykálló } \\
\hline Year (Y) & 3 & 12.548 & 25.88 & 0.001 & 6.362 & 7.84 & 0.017 & 0.116 & 0.64 & 0.616 & 0.069 & 0.75 & 0.561 & 0.023 & 1.40 & 0.331 & 0.291 & 0.96 & 0.421 \\
\hline Management (M) & 1 & 1066.667 & 2199.94 & $<0.001$ & 1053.507 & 1298.31 & $<0.001$ & 0.120 & 0.66 & 0.447 & 0.967 & 10.54 & 0.018 & 0.009 & 0.59 & 0.470 & 0.534 & 1.87 & 0.239 \\
\hline Main plot error & 3 & 0.994 & & & 2.154 & & & 0.287 & & & 0.193 & & & 0.072 & & & 0.089 & & \\
\hline Cultivar (C) & 2 & 29.675 & 61.20 & $<0.001$ & 13.532 & 16.68 & 0.004 & 0.289 & 1.59 & 0.279 & 0.726 & 7.91 & 0.021 & 0.048 & 3.00 & 0.125 & 0.191 & 0.78 & 0.657 \\
\hline $\mathrm{M} \times \mathrm{C}$ & 2 & 1.375 & 3.27 & 0.167 & 2.454 & 3.02 & 0.123 & 1.366 & 7.51 & 0.023 & 0.232 & 2.53 & 0.160 & 0.017 & 1.05 & 0.407 & 0.299 & 1.03 & 0.411 \\
\hline Subplot error & 6 & 0.485 & & & 0.811 & & & 0.175 & & & 0.092 & & & 0.016 & & & 0.132 & & \\
\hline
\end{tabular}

${ }^{\text {a }}$ Based on arcsine square root transformed data.

Integrated
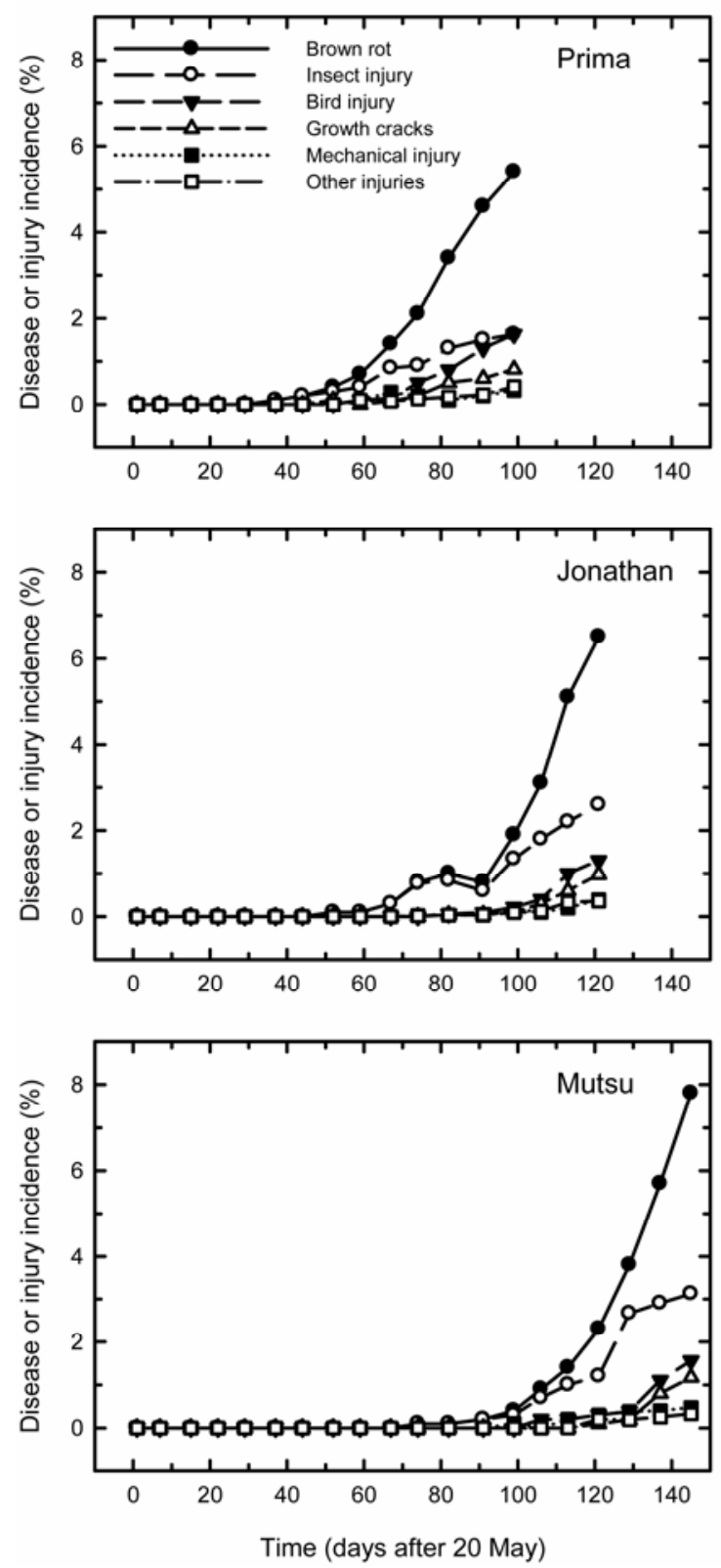

Organic
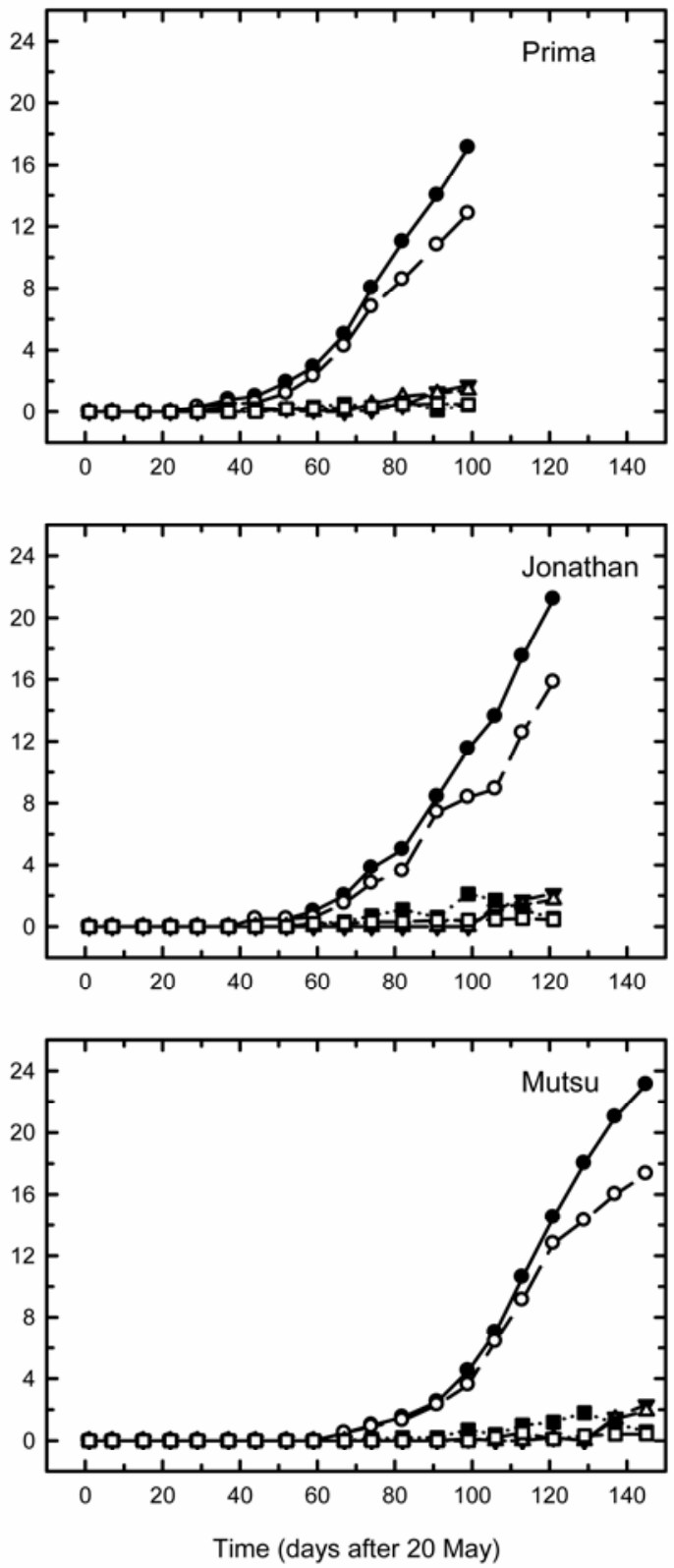

Fig. 1. Progress curves for incidence levels of brown rot and various injury types for three apple cultivars in integrated and organic blocks of the Eperjeske orchard in 2002 in Hungary. Each data point is the mean of four plots. Note different vertical axis scales for the integrated and organic management systems. 

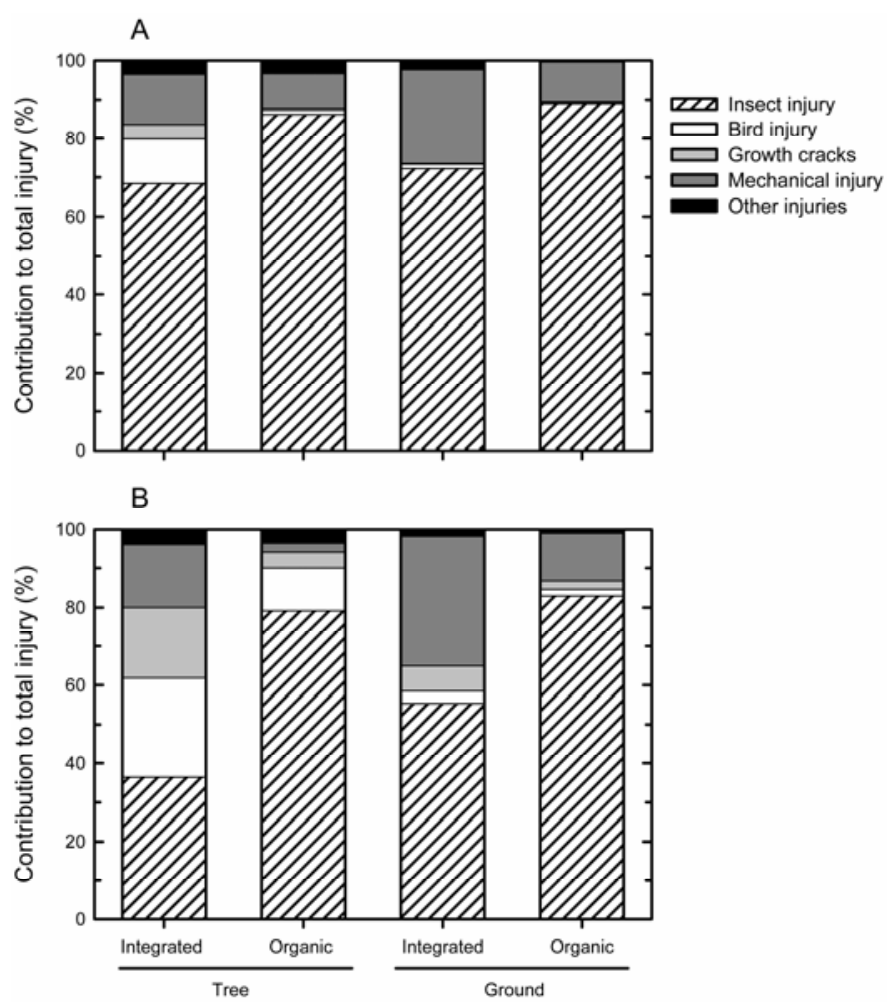

Fig. 2. Contribution of five injury types to the incidence of total injury at $\mathbf{A}$, 4 weeks before harvest and $\mathbf{B}$, at harvest, on fruit in the tree and on the ground in integrated and organic blocks of apple orchards at Eperjeske and Nagykálló, Hungary. Percentages based on data from two sites, 4 years (2002 to 2005), three cultivars (Prima, Jonathan, and Mutsu), and four plots per cultivar.
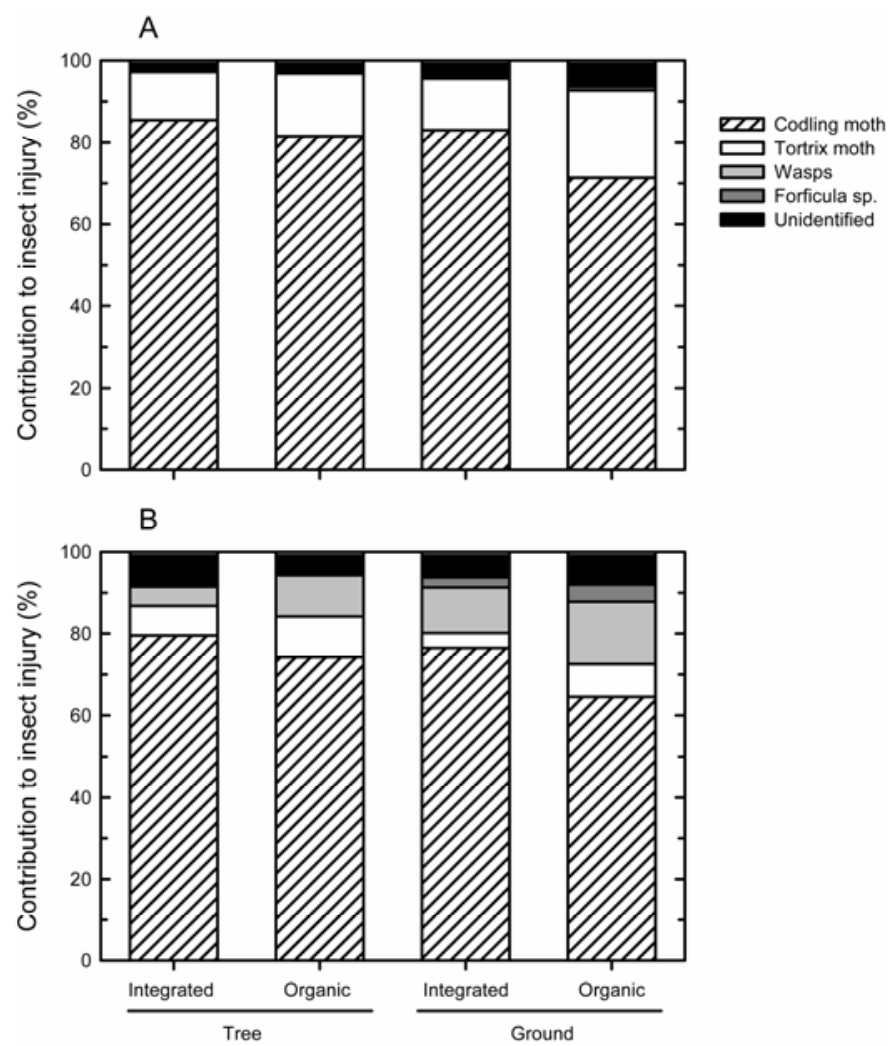

Fig. 3. Contribution of five insect groups to the incidence of total insect injury at $\mathbf{A}, 4$ weeks before harvest and $\mathbf{B}$, at harvest, on fruit in the tree and on the ground in integrated and organic blocks of apple orchards at Eperjeske and Nagykálló, Hungary. Percentages based on data from two sites, 4 years (2002 to 2005), three cultivars (Prima, Jonathan, and Mutsu), and four plots per cultivar. were quantified using the Jaccard similarity coefficient, $J$ (27). This index represents the proportion of the number of fruit where brown rot and a given injury type occurred jointly relative to the total number of fruit where at least one of the two was found: $J=$ $a /(a+b+c)$, where $a=$ number of fruit where both brown rot and the injury type were found together, $b=$ number of fruit where brown rot occurred alone, and $c=$ number of fruit where the injury type occurred alone. The significance of these interspecific associations was determined with a chi-square test for a $2 \times 2$ contingency table using SPASSOC.BAS software (27). A significant positive association means that brown rot and injury co-occurred together more often than expected if they were independent, while the opposite (less frequent co-occurrence of the two) would be the case for a significant negative association. Again, the analysis was done separately for the two management systems and for assessments 4 weeks preharvest and at harvest.

\section{RESULTS}

Brown rot and injury progress. ANOVA of final brown rot incidence indicated significant $(P<0.05)$ differences among years, management systems, and cultivars at both locations (Table 1). Results were very similar when disease severity was analyzed (data not shown). Among the five injury types, the incidence levels of insect injury and growth cracks also were affected significantly by cultivar and management system, while those of bird injury, mechanical injury, and other (unidentified) injuries generally were not (Table 1).

Data collected in the Eperjeske orchard in 2002 illustrate patterns of disease and injury progress typical of the eight siteyear combinations (Fig. 1). Brown rot developed more slowly and reached a lower incidence at harvest in the integrated orchard blocks (up to $7.8 \%$ final incidence for this site-year combination) compared with the organic blocks (up to $23.1 \%$ ). In addition, the disease developed later but attained higher levels as the cultivar ripening season increased from early-maturing Prima to latematuring Mutsu. Total injury incidence reached up to 6.3 and $22.1 \%$ in the integrated and organic blocks at Eperjeske in 2002, respectively. In all cases, insect injury was the injury type with the highest incidence. There was considerable overlap between the insect injury and brown rot progress curves up through midseason, while toward the end of the season the two curves separated, with brown rot incidence reaching higher levels. At the same time, the incidence levels of other injury types began to increase, but none of those reached levels $>2 \%$ (Fig. 1). Overall (across the 4 years and two sites), 94.3 to $98.7 \%$ of all injured fruit were also infected by $M$. fructigena.

Four weeks before harvest, insects were the leading cause of fruit injury, accounting for 68.6 and $86.3 \%$ of the injuries on fruit in the tree in the integrated and organic treatments, respectively (Fig. 2A). This percentage dropped considerably at the harvest assessment for the integrated $(36.6 \%)$ but not for the organic blocks (79.4\%) (Fig. 2B). In the former blocks, bird injury

TABLE 2. Analysis of variance of the effects of year (2002 to 2005) and management system (organic versus integrated) on the cumulative numbers of codling moth males trapped from 20 May to 30 September in apple orchards at Eperjeske and Nagykálló, Hungary

\begin{tabular}{llrrr}
\hline Source & df & \multicolumn{1}{c}{ MS } & \multicolumn{1}{c}{$F$} & \multicolumn{1}{c}{$P$} \\
\hline Eperjeske & & & & \\
$\quad$ Year & 3 & 394,336 & 7.67 & $<0.001$ \\
$\quad$ Management & 1 & $1,986,025$ & 38.64 & $<0.001$ \\
$\quad$ Error & 3 & 149,682 & & \\
Nagykálló & & & & \\
$\quad$ Year & 3 & 628,215 & 11.77 & $<0.001$ \\
$\quad$ Management & 1 & $2,842,920$ & 53.25 & $<0.001$ \\
$\quad$ Error & 3 & 121,294 & & \\
\hline
\end{tabular}


(25.4\%), growth cracks (18.2\%), and mechanical injury (16.1\%) all contributed appreciably to total injury at harvest; the corresponding percentages in the organic blocks were much lower. On dropped fruit on the ground, the relative contributions of insect injury and mechanical injury were higher while those of bird injury and growth cracks were lower than on fruit in the tree (Fig. 2).

Four weeks before harvest, 81.5 to $85.4 \%$ of the insect injury on fruit in the tree was caused by codling moth larvae, with the remainder caused mainly by the tortrix moth (Fig. 3A). On dropped fruit on the ground, especially in the organic blocks, codling moth damage was less dominant, while the relative percentage of tortrix moth damage was increased. By harvest, the relative importance of tortrix moth was lowered somewhat, and additional injury caused by wasps and Forficula sp. had occurred (Fig. 3B). At that time, injuries caused by the latter two insect groups were more frequent in the organic blocks and on fruit on the ground compared with the integrated treatment and fruit on the tree.

Monitoring of $\boldsymbol{C}$. pomonella. ANOVA of the cumulative numbers of trapped codling moth males indicated highly significant $(P<0.001)$ differences among years and management systems at both locations (Table 2). Moth flight activity was higher in the organic than in the integrated blocks in all years, as illustrated with data collected at Eperjeske in 2002 (Fig. 4). Codling moth flight activity increased after mid-June in both management systems and then remained high (above six male captures per day) in the organic orchard blocks.

Relationships between brown rot and injury types. Pearson's correlation coefficients, calculated on a subplot basis, showed that brown rot incidence correlated significantly with the

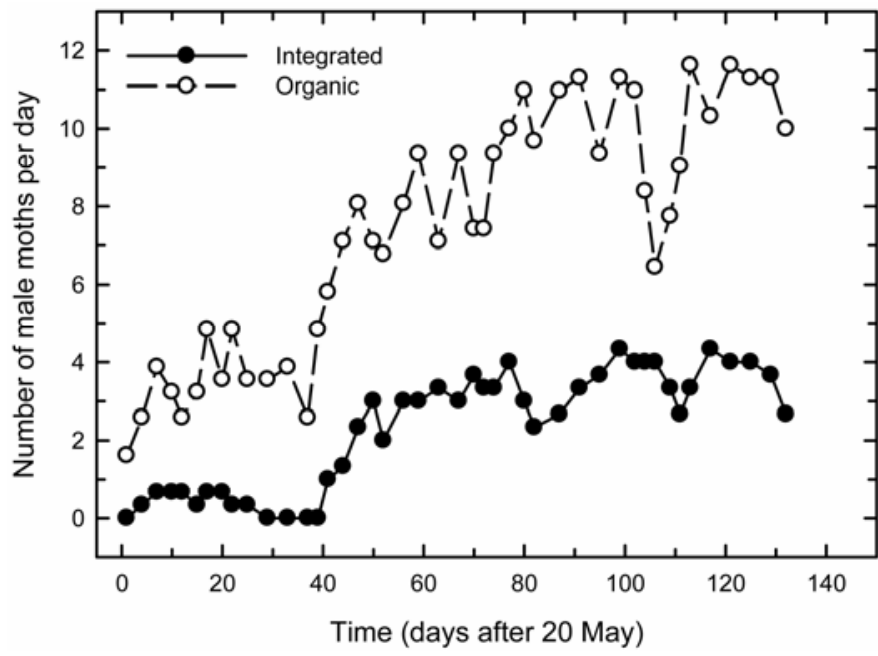

Fig. 4. Pheromone trap catches of codling moth males in integrated and organic blocks of the Eperjeske orchard in 2002 in Hungary. Each value is the mean of three traps in four plots. incidence of insect injury and the cumulative number of codling moth males at the early assessment date 4 weeks preharvest (Table 3). At the harvest assessment, two additional associations, those between brown rot and the incidence levels of bird injuries and growth cracks, were statistically significant. In every case, correlation coefficients were larger in organic than in integrated blocks.

Insect injury had the highest correlation coefficients with disease incidence among the various injury types examined (Table 3 ). Thus, the relationship between these two variables was investigated further by linear regression analysis (Fig. 5). This analysis revealed a highly significant $(P<0.001)$ relationship between brown rot incidence and insect injury incidence both at the early ( $r=0.907$ and 0.931 for integrated and organic plots, respectively) and the final assessment dates $(r=0.792$ and 0.929 for integrated and organic plots, respectively). While the slopes of the disease-insect injury relationship were significantly different from 1.0 for the integrated blocks (according to $t$ tests), they did not differ significantly from a 1:1 relationship for the organic blocks, further substantiating the close connection between insect injury and disease in the organic management system.

Results of the plot-based correlation analyses were supported by the finer-scale analysis of interspecific associations at the individual fruit level (data from Eperjeske 2002 shown for illustration in Table 4): (i) all associations between brown rot and injury were positive; (ii) the strongest (based on the Jaccard similarity coefficient) and most significant (based on chi-square values) associations were between brown rot and insect injury, while brown rot associations with bird injury, growth cracks, and mechanical injury were weaker; and (iii) brown rot associations with insect injury were stronger in the organic than in the integrated blocks.

\section{DISCUSSION}

Although it is well established that brown rot in pome fruits is closely associated with fruit injuries, this is the first study to provide season-long progress data on injury types and quantitative analyses of the relative importance of different types of injuries at different times in the growing season and across two distinct management systems. Most importantly, our results showed that (i) the level of fruit injury and the relative contribution of different wounding agents to the total injury level varied among cultivars, management systems, and position of fruit (tree or ground); (ii) although insect injury was the most common injury type in both management systems, the relative contribution of insects to the total injury incidence on fruit in the tree differed markedly between the integrated and organic blocks, with important implications for the value of insect management is suppressing brown rot in the two management systems; and (iii) fruit-to-fruit contact, considered a leading entry point for infection by $M$. fructigena in previous studies, was only of minor importance in the present study.

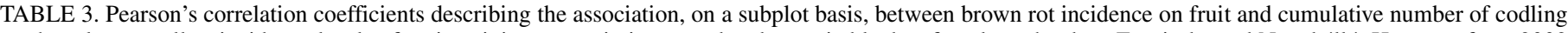

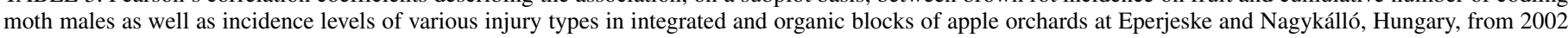
to $2005^{\mathrm{a}}$

\begin{tabular}{|c|c|c|c|c|c|c|c|c|}
\hline \multirow[b]{3}{*}{ Associations } & \multicolumn{4}{|c|}{ Early date (4 weeks pre-harvest) } & \multicolumn{4}{|c|}{ Final date (harvest) } \\
\hline & \multicolumn{2}{|c|}{ Integrated } & \multicolumn{2}{|c|}{ Organic } & \multicolumn{2}{|c|}{ Integrated } & \multicolumn{2}{|c|}{ Organic } \\
\hline & $r$ & $P$ & $r$ & $P$ & $r$ & $P$ & $r$ & $P$ \\
\hline Brown rot vs. codling moth & 0.754 & 0.0306 & 0.873 & 0.0046 & 0.709 & 0.0440 & 0.921 & 0.0012 \\
\hline Brown rot vs. insect injury & $\mathbf{0 . 8 3 7}$ & 0.0087 & 0.952 & 0.0001 & 0.817 & 0.0111 & 0.934 & 0.0007 \\
\hline Brown rot vs. bird injury & 0.324 & 0.2442 & 0.526 & 0.0811 & 0.684 & 0.0478 & 0.793 & 0.0221 \\
\hline Brown rot vs. growth cracks & 0.589 & 0.0642 & 0.430 & 0.1120 & 0.710 & 0.0439 & 0.721 & 0.0395 \\
\hline Brown rot vs. mechanical injury & 0.375 & 0.1424 & 0.331 & 0.2276 & 0.074 & 0.9694 & 0.182 & 0.7604 \\
\hline
\end{tabular}

a $n=96$ except for codling moth where $n=32$. Bold values indicate significance at $P<0.05$. 
Overall, 94.3 to $98.7 \%$ of all injured fruit were also infected by $M$. fructigena, whereas the incidence of brown-rotted fruit without visible injury was very low $(<2 \%)$. This supports previous laboratory and glasshouse investigations (46) documenting the importance of wounds in the epidemiology of brown rot of pome fruits. Also in agreement with previous studies $(26,48)$, our results emphasize that prevention of fruit injury is essential for the control of M. fructigena in apple orchards.

The level of fruit injury and the relative contribution of different wounding agents to the total injury level varied among cultivars and management systems. Fruit injury was more severe on the later-maturing cultivars, probably due to the longer exposure time to damage by insects and other agents. The considerably higher fruit injury levels in the organic orchard blocks (more than threefold on average) were likely due to the less effective insecticides available $(43,44)$ and the larger diversity of invertebrate populations, including pest species $(22,43)$.

Insect injury was the most common injury type in both management systems, but the relative contribution of insects to the total injury incidence on fruit in the tree at harvest differed markedly between the integrated $(36.6 \%)$ and organic $(79.4 \%)$ blocks. Thus, given the much higher overall injury incidence and the greater relative contribution of insects in the organic management system, any improvement in arthropod management has the potential to add significantly toward the reduction of injuryassociated brown rot in organic apple orchards. This applies particularly to management of the codling moth, the most important contributor to insect injury in this study. In the integrated management system, although the codling moth was also the major contributor to insect injury, overall insect injury incidence was low, indicating that there was little to be gained by intensifying codling moth management efforts.

Previous field research in an integrated apple orchard in Britain revealed that insect injury contributed between 15.6 and $26.8 \%$ of all entry points for $M$. fructigena (48), less than in the integrated orchard blocks in the present study. Although that study did not differentiate entry sites among insect species, the authors also noted that the primary insect pests were tortrix moth and codling moth larvae.

When fruit began to mature, we observed additional injurycausing insects such as wasps on fruit in the tree and on dropped fruit on the ground. At harvest, insects that do not cause fruit injuries, such as fruit flies, were also present in the organic but not in the integrated orchard blocks. Most likely, these insects were attracted by the volatiles associated with the relatively large numbers of decomposing fruit in the organic blocks, and they were present both on infested sporulating fruit on the ground and on injured fruit in the tree. Thus, these species may play a role in vectoring conidia and spreading the disease as was shown previously for Drosophila subobscura transmitting M. fructigena on apple (26) and for nitidulid beetles transmitting $M$. fructicola on stone fruits $(31,35)$.

In previous studies, birds such as starlings, blackbirds, and crows were identified as important wounding agents resulting in severe brown rot epidemics around harvest $(8,28,36,38,45,48)$. Xu et al. (48) determined a relative contribution of bird damage to the total brown rot incidence of 15.5 to $22.7 \%$ on apple fruit and $>50 \%$ on pear fruit by harvest. The relative contribution of bird
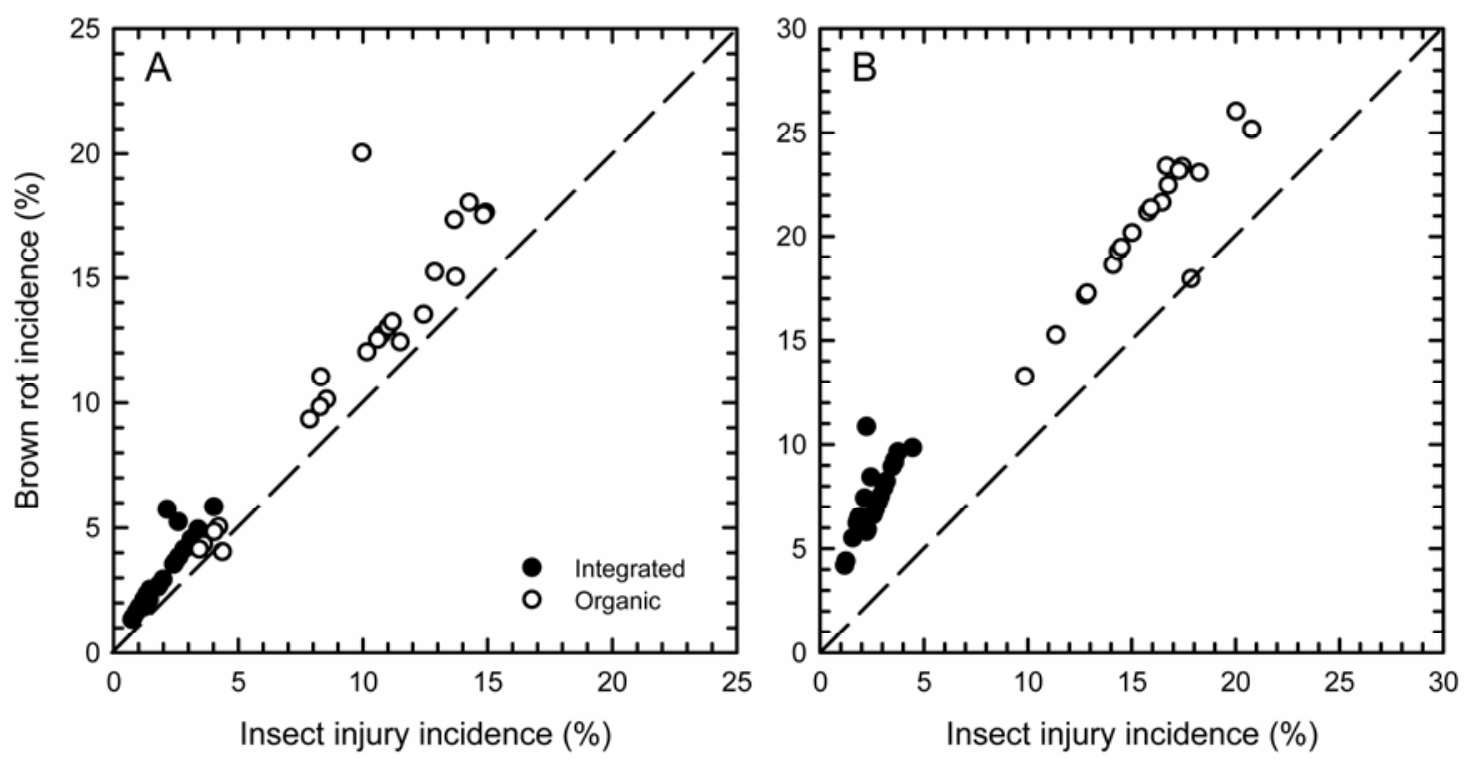

Fig. 5. Relationships between final brown rot incidence and insect injury incidence at $\mathbf{A}, 4$ weeks before harvest and $\mathbf{B}$, at harvest, in integrated $(\mathbf{O})$ and organic blocks (O) of apple orchards at Eperjeske and Nagykálló, Hungary, from 2002 to 2005. Each point represents data from a single site, a single year, and a single cultivar. The dashed line indicates a 1:1 relationship.

TABLE 4. Interspecific associations, on a per fruit basis, between presence and absence of brown rot and presence or absence of various injury types in integrated and organic blocks of the Eperjeske apple orchard in 2002

\begin{tabular}{|c|c|c|c|c|c|c|c|c|c|c|c|c|}
\hline \multirow[b]{3}{*}{ Associations } & \multicolumn{6}{|c|}{ Early date (4 weeks pre-harvest) } & \multicolumn{6}{|c|}{ Final date (harvest) } \\
\hline & \multicolumn{3}{|c|}{ Integrated } & \multicolumn{3}{|c|}{ Organic } & \multicolumn{3}{|c|}{ Integrated } & \multicolumn{3}{|c|}{ Organic } \\
\hline & Sign & Chi-square $^{a}$ & $J^{\mathrm{b}}$ & Sign & Chi-square & $J$ & Sign & Chi-square & $J$ & Sign & Chi-square & $J$ \\
\hline Brown rot vs. bird injury & + & $43.5 * * *$ & 0.167 & + & $6.74 * *$ & 0.054 & + & $53.9 * * *$ & 0.174 & + & $37.7 * * *$ & 0.112 \\
\hline Brown rot vs. growth cracks & + & 1.50 & 0.053 & + & $4.39 *$ & 0.029 & + & $37.1 * * *$ & 0.133 & + & $26.3 * * *$ & 0.073 \\
\hline Brown rot vs. mechanical injury & + & 1.50 & 0.053 & + & $42.4 * * *$ & 0.125 & + & $5.95^{*}$ & 0.047 & + & $5.40^{*}$ & 0.032 \\
\hline
\end{tabular}

${ }^{\text {a }}$ Chi-square values marked $* * *$, and $* * *$ are significant at $P=0.05,0.01$, and 0.001 , respectively.

${ }^{\mathrm{b}} J=$ Jaccard similarity coefficient: proportion of the number of fruit where brown rot and a given injury type occurred jointly relative to the total number of fruit where at least one of the two was found. 
damage in our study was similar, despite attempts to repel birds by predator-mimicking devices and shooting.

In their study in Britain, $\mathrm{Xu}$ et al. (48) noted that growth cracks were a leading entry point for $M$. fructigena, accounting for $39.2 \%$ of observed fruit rot of apple in one year (1997). This was due to postbloom frost, which caused severe russeting of the skin of surviving fruit, which later cracked as they expanded. In a year without late frost (1996), the relative importance of growth cracks was much lower $(14.7 \%)$. Our results revealed a similar relative contribution of growth cracks as observed by $\mathrm{Xu}$ et al. (48) in 1996. In general, the three cultivars used in this study are not highly susceptible to cracking. Furthermore, heavy rains, another common cause of fruit cracking (10), are infrequent around harvest in the Hungarian continental climate.

The relative contribution of mechanical injury, an injury type not considered by $\mathrm{Xu}$ et al. (48), was similar to that of growth cracks in the present study. Because fruit are often injured when they drop to the ground, the relative importance of mechanical injury was greater for fruit on the ground compared with those in the tree.

Fewer than $2 \%$ of the brown-rotted fruit in the present study showed no signs of wounding by other factors. In these cases, infection may have occurred via fruit-to-fruit contact. In contrast, fruit-to-fruit contact spread was considered a major factor in the study of $\mathrm{Xu}$ et al. (48) where a large proportion (44.4\%) of brown rot in one year was from contact spread. Moore (29) also reported a large proportion of contact spread of $M$. fructigena $(\approx 25 \%)$ in apple. In addition, infection via fruit-to-fruit contact was shown to be partly responsible for distinct clustering of diseased apple fruits in the tree canopy (38). In the high-density orchards included in the present study, fruit were hand-thinned to one fruit per cluster to reduce the likelihood of limb breakage and to produce equally-sized apples. This resulted in less chance for fruit-to-fruit contact spread of brown rot.

Our results have important implications for management of brown rot in apple orchards. In integrated orchards, highly effective synthetic insecticides are available to manage arthropod populations. Thus, compared with organic orchards, the injury profile is less dominated by insect injuries, and further improvements in brown rot control necessitate a multi-pronged approach against a diverse range of injury factors. In contrast, the key toward improved brown rot management in organic orchards is better codling moth management. Indeed, codling moth is perceived the most limiting factor in organic apple production worldwide $(25,42,43)$. Most commonly, Bacillus thuringiensis, granulosis viruses, rotenone, and summer oils are recommended as season-long spray applications against Lepidoptera insects such as codling moth in organic production systems $(2,40,41)$. Additionally, use of the sterile male technique (13), postharvest fruit removal, tree banding, and mating disruption (25) have been suggested. Based on economic considerations, only B. thuringiensis and oils were used against insects in the organic blocks in this study, resulting in relatively high codling moth damage. Previous research demonstrated that mating disruption in combination with two or three other control tactics can provide an acceptable level of codling moth control $(9,25,39,42)$, but the cost of this approach is considerably higher $(33,42)$. Sprayable, microencapsulated pheromone formulations that can be applied with standard spray equipment (rather than having to be hand-applied individually in the form of twist-tie dispensers) could substantially reduce the cost of application (23).

To further improve efficacy and economic feasibility of codling moth control, pest forecasting models $(1,5,24,30,32)$ may be used to adjust the timing of insecticide applications to pest population dynamics. Since organically approved fungicides (primarily sulfur and copper compounds) provide less effective protective control compared with systemic fungicides commonly used in integrated and conventional orchards $(17,18)$, improved insect control is essential in the brown rot management of organic apple orchards. Overall, and across management systems, dynamics of brown rot development in relation to wounding agents needs to be included in an efficient brown rot management system.

\section{ACKNOWLEDGMENTS}

We thank L. Halász, J. Katona, and J. Holb Sr., for their excellent cooperation. The study was supported in part by the Hungarian Scientific Research Fund and a János Bolyai Research Fellowship awarded to I. J. Holb.

\section{LITERATURE CITED}

1. Ahmad, T. R., Ali, M. A., and Hamad, B. S. 1995. Using degree-day model to determine the optimum spray timing for codling moth Cydia pomonella (L.) (Lep., Olethreutidae). J. Appl. Entomol. 119:143-144.

2. Altieri, M. A., Davis, J., and Burroghs, K. 1983. Some agroecological and socioeconomic features of organic farming in California: A preliminary study. Biol. Agric. Hortic. 1:97-107.

3. Batra, L. R. 1991. World Species of Monilinia (Fungi): Their Ecology, Biosystematics and Control. Mycologia Memoir 16. J. Cramer, Berlin.

4. Berrie, A. M. 1989. Storage rots of apple and pear in South East England 1980-88: Incidence and fungicide resistance. Pages 229-239 in: Integrated Control of Pome Fruit Diseases, 1989. C. Gessler, D. J. Butt, and B. Koller, eds. IOBC, Brissago, Switzerland.

5. Blago, N., and Edland, T. 1991. Forecast of egg-laying activity of Cydia pomonella in Europe - First results using a modified prognosis model. J. Plant Dis. Prot. 98:378-384.

6. Burchill, R. T., and Edney, K. L. 1972. An assessment of some new treatments for control of rotting of stored apples. Ann. Appl. Biol. 72:249255.

7. Byrde, R. J. W. 1954. Observation on the sporulation of Sclerotinia fructigena on mummified apples and plums in late spring and summer. Pages 163-166 in: Report of Agricultural and Horticultural Research. Station, Bristol, UK.

8. Byrde, R. J. W., and Willetts, H. J. 1977. The Brown Rot Fungi of Fruit. Their Biology and Control. Pergamon Press, Oxford.

9. Caprile, J., Klonsky, K., Mills, N., McDougall, S., Micke, W., and van Steenwyk, B. 1994. Insect damage limits yield, profits of organic apples. Calif. Agric. 48(6):21-28.

10. Childers, N. F., Morris, J. R., and Sibbett, G. S. 1995. Modern Fruit Science: Orchard and Small Fruit Culture. Horticultural Publications, Gainesville, FL.

11. Cross, J. V., and Dickler, E. 1994. Guidelines for integrated production of pome fruits in Europe. Technical guideline III. IOBC/WPRS Bull. 17:1-8.

12. Croxall, H. E., Collingwood, C. A., and Jenkins, J. E. E. 1951. Observations on brown rot (Sclerotinia fructigena) of apples in relation to injury caused by earwigs (Forficula auricularia). Ann. Appl. Biol. 38:833843 .

13. Dyck, V. A., and Gardiner, M. G. T. 1992. Sterile-insect release programme to control the codling moth Cydia pomonella (L.) (Lepidoptera: Olethreutidae) in British Columbia, Canada. Acta Phytopathol. Hun. 27:219-222.

14. Garic, R., Stamenkovic, S., and Canak, M. 1990. The effect of Cydia molesta on the incidence of Monilinia spp. on quince fruits. EPPO Bull. 20:603-606.

15. Holb, I. J. 2003. Analyses of temporal dynamics of brown rot development on fruit in organic apple production. Int. J. Hortic. Sci. 9:97100.

16. Holb, I J. 2004. Yield loss and disease development of Monilinia fructigena (Aderh. \& Ruhl.) Honey in organic apple orchard. J. Agr. Sci. 15:6-8.

17. Holb, I. J., Heijne, B., and Jeger, M. J. 2003. Summer epidemics of apple scab: The relationship between measurements and their implications for the development of predictive models and threshold levels under different disease control regimes. J. Phytopathol. 151:335-343.

18. Holb, I. J., Heijne, B., Withagen, J. C. M., Gáll, J. M., and Jeger, M. J. 2005. Analysis of summer epidemic progress of apple scab at different apple production systems in the Netherlands and Hungary. Phytopathology 95:1001-1020.

19. Holb, I. J., and Scherm, H. 2007. Temporal dynamics of brown rot in different apple management systems and importance of dropped fruit for disease development. Phytopathology 97:1104-1111.

20. Horne, A. S. 1933. Biological work on fruit. Pages 279-300 in: Report of the Food Investigation Board for 1932, Interscience Publishers, London.

21. IFOAM. 1989. Basic Standards for Organic Agriculture. Tholey-Theley Press, New York. 
22. IFOAM, 2000. IFOAM Basic Standards for Organic Production and Processing. Tholey-Theley Press, New York.

23. Il'ichev, A. L., Stelinski, L. L., Williams, D. G., and Gut, L. J. 2006. Sprayable microencapsulated sex pheromone formulation for mating disruption of Oriental fruit moth (Lepidoptera: Tortricidae) in Australian peach and pear orchards. J. Econ. Entomol. 99:2048-2054.

24. Jorgensen, C. D., Martinsen, M. E., and Westover, L. J. 1979. Validating Michigan State University's codling moth model (MOTHMDL) in an arid environment: A test in Utah. Great Lakes Entomol. 12:203-212.

25. Judd, G. J. R., Gardiner, M. G. T., and Thomson, D. R. 1997. Control of codling moth in organically-managed apple orchards by combining pheromone-mediated mating disruption, post-harvest fruit removal and tree banding. Entomol. Exp. Appl. 83:137-146.

26. Lack, H. 1989. The spread of apple brown rot (Monilinia fructigena) by insects. Ann. Appl. Biol. 115:221-227.

27. Ludwig, J. A., and Reynolds, J. F. 1988. Statistical Ecology. Wiley, New York.

28. Mitterling, L. A. 1965. Bird damage on apples. Proc. Am. Soc. Hortic. Sci. 87:66-72.

29. Moore, M. H. 1950. Brown rot of apples: Fungicide trials and studies of the relative importance of different wound-agents. J. Hortic. Sci. 25:225-234.

30. Morgan, D., and Solomon, M. 1996. Pest-man: A forecasting system for orchard pests. Acta Hortic. 416:273-277.

31. Ogawa, J. M. 1957. The dried fruit beetle disseminates spores of peach brown rot fungus. (Abstr.) Phytopathology 47:530.

32. Pitcairn, M. J., Zalom, F. G., and Rice, R. E. 1992. Degree-day forecasting of generation of Cydia pomonella (Lepidoptera, Tortricidae) populations in Calfornia. Environ. Entomol. 21:441-446.

33. Rader, J. S., Walser, R. H., Jorgensen, C. D., Williams, C. F., and Davis, T. D. 1985. Efficacy and economics of codling moth control in organic and conventional pome fruit production. Biol. Agric. Hortic. 4:315-321.

34. Sharma, R. L., and Kaul, J. L. 1990. Mode of entry and histopathological changes induced by Monilinia species in apple fruit. Indian Phytopathol. 43:113-115.

35. Tate, K. G., and Ogawa, J. M. 1975. Nitidulid beetles as vectors of Monilinia fructicola in California stone fruit. Phytopathology 65:977-983.

36. Tobin, M. E., Dolbeer, R. A., and Woronecki, P. P. 1989. Bird damage to apples in the Mid-Hudson Valley of New York. HortScience 24:859.
37. Van Leeuwen, G. C. M., Holb, I. J., and Jeger, M. J. 2002. Factors affecting mummification and sporulation of pome fruit infected by Monilinia fructigena in Dutch orchards. Plant Pathol. 53:787-793.

38. Van Leeuwen, G. C. M., Stein, A., Holb, I. J., and Jeger, M. J. 2000. Yield loss caused by Monilinia fructigena (Aderh. \& Ruhl.) Honey, and spatiotemporal dynamics of disease development. Eur. J. Plant Pathol. 106:519528 .

39. Vossen, P., Jolly, D., Meyer, R., Varela, L., and Biodgett, S. 1994. Disease, insect pressure make organic grower production risky in Sonoma County. Calif. Agric. 48(6):29-36.

40. Wearing, C. H. 1979. Integrated control of apple pests in New Zealand. 10. Population dynamics of codling moth in Nelson. N. Z. J. Zool. 6:165199.

41. Wearing, C. H. 1993. Control of codling moth with commercial preparation of granulosis virus. Pages 146-151 in: Proc. 46th N. Z. Plant Protection Conf., Lincoln, New Zealand.

42. Wearing, C. H., Walker, J. T. S., Thomas, W. P., Clearwater, J. R. Suckling, D. M., Charles, J. G., Shaw, P. W., White, V., and Burnip, G. 1995. Pest control for organic apple production in New Zealand. The Orchardist New Zeal. 68:22-27.

43. Weibel, F., and Häseli, A. 2003. Organic apple production with emphasis on European experiences. Pages 551-583 in: Apples: Botany, Production and Uses. D. C. Ferree, and I. J. Warrington, eds. CAB International, Wallingford, UK.

44. William, R. D. 1981. Complementary interactions between weeds, weed control practices and pests in horticultural cropping systems. HortScience 16:508-513.

45. Wormald, H. 1954. The brown rot disease of fruit trees. MAFF Technical Bulletin 3, Interscience Publishers, London.

46. Xu, X. M., and Robinson, J. D. 2000. Epidemiology of brown rot (Monilinia fructigena) on apple: Infection of fruits by conidia. Plant Pathol. 49:201-206.

47. Xu, X. M., Guerin, L., and Robinson, J. D. 2001. Effects of temperature and relative humidity on conidial germination and viability, colonization and sporulation of Monilinia fructigena. Plant Pathol. 50:561-568.

48. Xu, X. M., Robinson, J. D., Berrie, A. M., and Harris, D. C. 2001. Spatiotemporal dynamics of brown rot (Monilinia fructigena) on apple and pear. Plant Pathol. 50:569-578. 